\title{
Análise da relação entre desmatamento e bem-estar da população da Amazônia Legal
}

\author{
Rodolfo Coelho Prates ${ }^{1}$ \\ Carlos José Caetano Bacha²
}

\begin{abstract}
Resumo: Este artigo analisa, empiricamente, a relação entre o desmatamento da floresta amazônica e o bem-estar da população local, mensurando os impactos de uma redução da área desmatada sobre o bem-estar. Utilizou-se o Indice de Desenvolvimento Humano Municipal (IDH-M) como indicador de bem-estar. Para isso, com base nos dados em nível municipal do Censo Agropecuário de 1995 foi estimada, para cada estado, uma função de produção Cobb-Douglas com três fatores de produção: terra, capital e trabalho. Com a função de produção e por meio do método de programação não linear (condições de Kuhn-Tucker), verificou-se a dimensão do impacto sobre o PIB agropecuário e do agronegócio quando há uma restrição na utilização do fator terra de modo a cumprir a legislação florestal vigente. Com base nos novos valores para o PIB, calculou-se o índice de renda que, combinado com os índices de educação e longevidade, produziram um novo IDH-M para alguns estados da Amazônia. Os resultados apontam que há alterações pequenas no IDH-M, apesar de serem bastante expressivas no nível de renda, quando se adotam restrições para a utilização da terra.
\end{abstract}

Palavras-chaves: Amazônia, desmatamento, bem-estar, programação não linear.

Abstract: This paper analyses the empirical relationship between Amazonian rainforest deforestation and local population welfare, measuring the impact on welfare if the deforestation area has to be reduced. The Municipal Human Development Index (MHDI) was used to measure welfare. Using 1995 Agriculture Census dataset, a Cobb-Douglas production function was estimated considering three production inputs: capital, land and labor. Applying a nonlinear programming method (Kuhn-Tucker conditions) on the

\footnotetext{
${ }^{1}$ E-mail: rdlps@bol.com.br

${ }^{2}$ E-mail: cjcbacha@esalq.usp.br
} 
results generated by the production function, the impacts of land constraints on agriculture and agribusiness incomes could be calculated, generating a new value of income for each Amazonian state. Combining new values of income with education and health indexes, a new MHDI was estimated for some Amazonian states. Results point out MHDI would have small reductions, despite significant reductions in some states income, if some restrains would be established on arable land use.

Key-words: Amazonian region; Deforestation; Welfare; Nonlinear programming.

Classificação JEL: C61; I31; Q23.

\section{Introdução}

O desenvolvimento das economias - tanto em países tropicais quanto em países localizados em regiões subtropicais ou até mesmo próximas ao círculo polar, como o Canadá e a Finlândia - implica, necessariamente, certo grau de desmatamento. E justamente nos países tropicais, os quais se encontram em vias de desenvolvimento e onde existem as maiores áreas florestais nativas, é que o desmatamento vem se acentuando.

O desenvolvimento da região amazônica não é recente. Mas é a partir da década de 1960 que ele se acelerou. A afluência de pessoas e de capitais, associada à construção de eixos rodoviários, transformou a paisagem de grandes parcelas da região por meio da retirada da cobertura vegetal, seguida da implantação de atividades agropecuárias e da construção de cidades, por exemplo. Disso resultou que, entre 1960 e 1995, o PIB da região amazônica cresceu 12 vezes, enquanto o PIB do Brasil como um todo registrou crescimento de pouco mais de cinco vezes (GOMES e VERGOLINO, 1997).

Um dos reflexos negativos dessa expansão do PIB é o alto custo ambiental, o qual pode ser comprovado pela grande área desmatada anualmente na região. Entre meados da década de 1970, quando foram registradas avaliações preliminares por meio das imagens geradas pelo satélite Landsat, e 2006, a área desmatada na Amazônia Legal ultrapassou os 70 milhões de hectares, o que equivale a uma área superior à soma das áreas dos estados que compõem a região Sul do País (HOMMA, 2006).

Na região amazônica vivem mais de 21 milhões de pessoas, segundo o Censo Demográfico de 2000, as quais geraram, nesse mesmo ano, renda superior a $\mathrm{R} \$ 73$ bilhões em bens e serviços (que é o PIB regional). Portanto, a região não se caracteriza pelo total vazio demográfico (ainda que isso ocorra em certas áreas da região), embora careça de muitos investimentos em infraestrutura que garantam condições mínimas de bem-estar para a população - em 2000, a região tinha o segundo menor Índice de Desenvolvimento Humano do País $(0,725)$, acima 
somente do Nordeste $(0,675)$. Esse último dado suporta manifestações sobre a necessidade de se continuar a expandir as atividades econômicas e, consequentemente, a renda na Amazônia.

Diante do exposto surge a indagação se a ação de desmatar gera ganhos efetivos à sociedade, uma vez que é certa a perda ambiental. A esse respeito é possível constatar dentro da literatura específica algumas controvérsias.

A primeira delas refere-se ao fato de que maiores níveis de desmatamento geram mais área para a agropecuária, a qual contribui para o aumento da renda. Porém, a renda da agropecuária pode depender mais das produtividades do capital e do trabalho do que da área cultivada propriamente dita.

A segunda controvérsia é a confusão entre renda e bem-estar social. $\mathrm{O}$ procedimento mais usual para mensurar o bem-estar é por meio do cálculo do Indice de Desenvolvimento Humano (IDH). Supõe-se que um maior nível de renda implica maior IDH. No entanto, pode-se ter maior IDH sem a participação significativa da renda gerada pelo setor agropecuário. Municípios em que predominam atividades econômicas essencialmente urbanas, ou que recebam maiores repasses do governo federal, contam com melhores serviços de educação e saúde e, portanto, podem ter maiores níveis de IDH.

Motivado pelas dúvidas apresentadas anteriormente, o objetivo geral deste artigo é analisar a relação entre o desmatamento da região da Amazônia Legal e o bem-estar de sua população, avaliando em que proporção uma restrição ao desmatamento impacta negativamente sobre o bem-estar.

Os objetivos específicos são:

1. Verificar a importância do fator terra, dentre os demais fatores, como determinante da composição da renda agropecuária por meio da estimativa de uma função de produção para a Amazônia Legal e para os estados que a compõem;

2. Avaliar o impacto da redução na área agrícola (caso haja um controle mais efetivo do desmatamento) sobre a geração de renda e o bem-estar da população dos estados da Amazônia.

\section{Revisão Bibliográfica}

Há ampla literatura sobre como medir bem-estar, sobre sua evolução e sua associação com o meio ambiente. Nesta seção, o foco são os trabalhos que se referem à análise do bem-estar na Amazônia Legal. Há, também, expressiva literatura sobre como usar a função de produção para analisar os impactos da terra sobre a produção agropecuária, mas que se referem a outros países que não o Brasil. Ambas as literaturas são ressaltadas de modo a evidenciar que os objetivos supracitados não foram ainda tratados na literatura disponível. 
Os trabalhos realizados sobre o bem-estar são de duas naturezas: os de cunho teórico (SEN, 1999; MUKHOPADHAYA, 2001; ISLAM e CLARKE, 2001) e os de aplicação empírica. Os primeiros estudos empíricos sobre o bem-estar não são recentes. Especificamente sobre os trabalhos brasileiros, há o destaque para os que consideram as regiões onde se encontram os melhores indicadores de bem-estar.

Barros, Mendonça e Duarte (1997) investigaram os mecanismos da distribuição de renda e os relacionaram com os aspectos referentes à desigualdade, pobreza e bem-estar no Brasil. Feito isso, eles compararam os resultados brasileiros com os de outros países, particularmente os da América Latina. Com relação ao Brasil, os autores concluem que a distribuição de renda melhorou levando a uma diminuição da pobreza e a um aumento no nível de bem-estar.

Marinho, Soares e Benegas (2003) estimaram medidas de eficiência técnica dos estados brasileiros para a geração de bem-estar, entre 1986 e 1988. Para estabelecer padrões de comparação, os autores implantaram três formas para medir o bem-estar: a medida de Sen, o PIB per capita e o Índice de Desenvolvimento Humano (IDH). Todas as medidas apontaram para os mesmos resultados: São Paulo, Rio Grande do Sul, Amazonas, Roraima e Amapá são os estados mais eficientes na geração de bem-estar. Resultado semelhante foi obtido por Ramos e Ávila (2000). Com base na Pesquisa Nacional por Amostra de Domicílios (PNAD) para 1992 e 1996, esses autores compararam o nível de bem-estar entre dez regiões metropolitanas do Brasil, bem como sua evolução ao longo do período analisado. Os resultados apontaram um maior nível de bem-estar entre as regiões metropolitanas do Sul, seguidas pelo Sudeste e Nordeste.

Em recente trabalho desenvolvido por Calentano e Veríssimo (2007a), é verificada a evolução dos indicadores sociais propostos nos "Objetivos de Desenvolvimento do Milênio" para os Estados da Amazônia Legal. O ranking de estados com melhor situação é: (1ํo) Mato Grosso, (2o) Amapá, (3o) Pará, (4oㅜ)

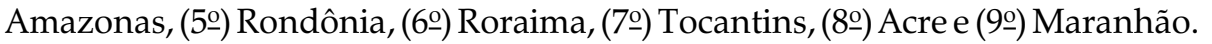

Fatores que promovem a melhoria do bem-estar, principalmente os relacionados à agricultura, também foram analisados em alguns trabalhos. $\mathrm{O}$ de Sarris (2001) salienta que o crescimento da agropecuária pode diminuir o nível de pobreza, ou seja, melhorar o nível de bem-estar, por meio de dois mecanismos: o direto e o indireto. $\mathrm{O}$ direto se deve ao fato de que o crescimento agrícola diminui a pobreza em áreas rurais; e o indireto decorre de que o crescimento da agricultura contribui para o crescimento de toda a economia, que, por sua vez, contribui para a diminuição da pobreza em geral.

Visão complementar à de Sarris é apresentada por Bravo-Ortega e Lederman (2005), os quais mostram que o desenvolvimento agropecuário tem efeito positivo sobre o bem-estar social. No entanto, esses autores ressaltam que o desenvolvimento de outros setores tem efeito superior sobre o bem-estar social quando comparado ao agrícola. 
Bonelli (2001) avaliou quantitativamente o crescimento do setor agropecuário e seus desdobramentos sobre a geração de renda, o crescimento populacional, a arrecadação de impostos e o desenvolvimento humano em 23 espaços geoeconômicos brasileiros (municípios ou conjunto de municípios contíguos) entre 1970 e 2000. Segundo o autor, apesar de os índices que mensuram as variáveis supracitadas para a região da Amazônia estarem abaixo ou próximos de 0,5 , que caracteriza uma situação de baixa qualidade de vida, houve crescimento no período analisado, sendo possível concluir que o crescimento da renda agropecuária está associado diretamente à melhora das condições de vida da população.

Walker et al. (1997) analisaram o processo de desenvolvimento agrícola ao longo do eixo da rodovia Transamazônica e o seu impacto sobre o bem-estar numa amostra de 132 produtores rurais no ano de 1993. Os resultados mostraram que $8,3 \%$ dos produtores rurais tiveram degradação de sua situação, 32,5\% mantiveram a posição original e 59,2\% melhoraram de situação.

Existem muitos trabalhos a respeito das transformações ambientais e seus desdobramentos sobre o bem-estar social. Tais estudos abrangem mudanças climáticas (HASSELMANN, 1999; FÜSSEL, 2007), gestão de águas (RUIJS, 2007), políticas de conservação (OLSON, 2000; GERLAGH e KEYZER, 2003) e poluição internacional (ZAGONARI, 1998), por exemplo.

E dentre toda a gama de associações entre o meio ambiente e o bem-estar, há também a relação deste último com o desmatamento. Um dos primeiros trabalhos a relacionar o bem-estar (qualidade de vida) com o desmatamento foi o de Diener (1995), o qual incorporou a variável desmatamento à metodologia do índice de qualidade de vida.

Particularmente em relação ao desmatamento na Amazônia, a literatura aponta fatores que o determinam. Alguns trabalhos priorizam um fator em particular, como a construção e pavimentação de estradas ou outras melhorias da infraestrutura (LAURANCE et al., 2004, WEINHOLD e REIS, 1999), ou o avanço da pecuária (MARGULIS, 2003), da soja (FEARNSIDE e GRAÇA, 2006) ou a influência da população (BARRETO et al., 2005), por exemplo. No entanto, é a combinação desses e de outros fatores aqui não relacionados e sua interdependência que impulsionam o desmatamento. Uma visão particular é a de Brandão, Rezende e Marques (2005), os quais apontam que o avanço da soja na região entre 1999 e 2004 não impactou sobre o desmatamento, pois seu crescimento esteve articulado com a conversão de pastagens em áreas destinadas à sojicultura. Além disso, os autores ressaltam que o aumento da produção de soja na região irá elevar o preço da terra, mitigando as atividades antieconômicas da região, as quais, sim, causam o desmatamento. No entanto, visão diferente da desses autores tem Volpi (2008, p. 13), o qual argumenta sobre os impactos indiretos que a expansão da soja tem sobre o desmatamento da Amazônia, ao expulsar a pecuária para novas áreas antes ocupadas por florestas. 
Independente dos fatores causadores, a dinâmica do desmatamento tem algumas implicações sobre o IDH. No momento em que ocorre desmatamento, o IDH é superior ao das áreas de floresta, devido ao aumento de renda gerado pela extração madeireira. E nas áreas já desmatadas, onde a atividade da agropecuária se instala, o IDH é semelhante ao das áreas de floresta (CALENTANO e VERÍSSIMO, 2007b). Azevedo e Pasquis (2006), ao analisarem o estado de Mato Grosso, verificaram que as diferenças socioeconômicas são muito semelhantes em municípios com diferentes níveis de desmatamento, principalmente naqueles onde se instalou a pecuária. Diniz et al. (2007) verificaram que as atividades que promovem o desmatamento pouco contribuem para a promoção da desigualdade da renda.

Por sua vez, nas localidades onde há a predominância do agronegócio no norte de Mato Grosso, em que existem as atividades de comercialização de insumos, máquinas e implementos agrícolas e a produção propriamente dita e sua comercialização, o nível de crescimento é superior à média do estado, o que sugere uma melhora da renda e, consequentemente, do IDH (SOUZA, 2007). Vale destacar, porém, que pode ser a comercialização o fator preponderante na melhora do IDH e não a atividade agropecuária.

No universo dos trabalhos empíricos em economia, geralmente há a necessidade de se estimar funções, quer sejam de utilidade, de custo, de lucro ou de produção. E uma função bastante utilizada nesse contexto é a função de produção Cobb-Douglas, principalmente em pesquisas de economia agrícola, visto que ela apresenta propriedades desejadas que tornam sua estimação e sua análise mais cômodas. Muitos estudos se concentram apenas na estimação da própria função de produção (HAYAMI, 1970; CHOWDHURY, NAGADEVARA e HEADY, 1975), outros testam se determinado setor apresenta retornos constantes de escala (ECHEVARRIA, 1998). Por meio das funções de produção, pode-se verificar a elasticidade de substituição entre os fatores de produção utilizados (MURATA e LOPES, 2006), além de ser possível determinar o nível de produtividade e o progresso tecnológico de um determinado setor (ANDZIO-BIKA e WEI, 2005; BINICI, DEMIRCAN e ZALAUF, 2006).

Como exemplo de estimativas mais recentes de função de produção para a agropecuária tem-se o estudo de Echevarria (1998), que utilizou a função Cobb-Douglas com três fatores de produção (terra, capital e trabalho) para testar se o setor agrícola do Canadá apresenta retornos constantes de escala entre 1971 e 1991. Andzio-Bika e Wei (2005) também incorporaram o fator terra na função de produção Cobb-Douglas para analisar o impacto de cada fator no crescimento da produtividade agrícola da China entre 1989 e 2002. Kamat, Tupe e Kamat (2007) analisaram o crescimento do PIB agrícola da Índia de 1970-71 a 2002-03 por meio da função de produção Cobb-Douglas. No caso do Brasil, Barros, Costa e Sampaio (2004) utilizaram a função Cobb-Douglas para analisar a eficiência técnica das empresas agrícolas do pólo de Petrolina e Juazeiro, no estado de Pernambuco. 
Com a função de produção, há a possibilidade de se utilizar técnicas de programação (linear ou não linear) para resolver problemas de restrição (igualdade ou desigualdade). Nesse aspecto, Hardie, Parks e van Kooten (2004) analisaram os instrumentos da política econômica para o uso do solo por meio das técnicas de programação não linear utilizando a função de produção Cobb-Douglas.

A partir da função de produção (Cobb-Douglas) e das técnicas de programação não linear, Galor, Moav e Vollrath (2005) demonstraram que as condições geográficas das propriedades agrícolas afetam negativamente a implantação das instituições de promoção do capital humano e, dessa forma, a transição de uma economia agrícola para industrial, gerando, assim, diferenças na renda real per capita.

\section{Referencial teórico e analítico: o bem-estar na análise econômica}

Comumente, o termo bem-estar reflete uma multiplicidade de significados, tais como condições de vida, liberdade, satisfação e felicidade. Por ter uma aceitação comum e por ser algo universalmente desejável, o bem-estar dos indivíduos ou da sociedade sempre despertou o interesse investigativo de vários campos do conhecimento, entre eles o da medicina, da ciência política, da economia e da filosofia. E foi justamente no campo filosófico que o tema do bem-estar despertou as primeiras reflexões sobre seu desenvolvimento e o que ele reflete e representa ao homem. O filósofo grego Aristóteles dedicou parte do seu livro Ética a Nicômaco para o estudo da eudaimonia, palavra grega para a felicidade. Para ele, a felicidade depende da "posse de bens reais aos quais a razão imporá uma justa medida, um meio termo, uma mistura ou combinação de prazer e inteligência" (SANTOS, 2001, p. 19).

Em A Riqueza das Nações, de Adam Smith, já no século XVIII, o bem-estar se ingressou sutilmente à gama de objetos da análise econômica com a roupagem da utilidade, na medida em que a melhora do bem-estar da sociedade era dependente do aumento do nível de utilidade dos indivíduos. Mas foi com o trabalho de Mill (1983) que a economia incorporou definitivamente o conceito utilitarista, embora esse autor não tenha estabelecido o princípio de maximização da utilidade como o objeto da racionalidade humana (COOTER e RAPPOPORT, 1984).

Entre 1870 e 1890, o bem-estar econômico foi formalizado como a maximização da utilidade pelos indivíduos, assim como as empresas maximizam o lucro. Como, nas visões de Marshall e Pigou, a utilidade representa aspectos materiais e não materiais, os economistas estavam aptos a considerar apenas os aspectos materiais, mas isso não deixaria de evidenciar as condições de bem-estar, na medida em que havia uma relação positiva entre os bens materiais e não materiais (ACKERMAN, 1997). 
Ainda no último quartel do século XIX, economistas como William Stanley Jevons e Vilfredo Pareto questionaram a quantificação da utilidade, ou seja, questionaram se a representação cardinal para medir a utilidade seria possível nos aspectos práticos.

Diante do impasse em mensurar o bem-estar econômico a partir de funções cardinais, os economistas encontraram uma forma de resolver tal problema por meio do Critério de Pareto, o qual estabelece que se uma ordenação social se altera de $\left(c^{1}, \ldots, c^{n}\right)$ para $\left(c^{1^{\prime}}, \ldots, c^{n^{\prime}}\right)$, em que $c^{i}(i$ variando de $1, \ldots, \mathrm{n})$ representam as cestas de consumo, e ninguém se encontra em situação pior à inicial e ao menos uma pessoa se encontra em situação melhor à inicial, diz-se que o bem-estar melhorou (DEATON e MUELLBAUER, 1980). A racionalidade dos agentes econômicos e a estrutura de competição perfeita constituem a base para a formulação do Critério de Pareto.

O Critério de Pareto não fornece subsídios para incluir elementos redistributivos, por ser um critério exclusivamente ordinal, ou seja, não permite qualquer tipo de relação cardinal entre as variações de utilidade.

Contribuindo na discussão, John Hicks e Nicholas Kaldor formularam o critério de compensação, o qual é uma tentativa de superação das limitações do Critério de Pareto. O critério de compensação diz que se os ganhos dos agentes beneficiados fossem maiores que a perda dos agentes prejudicados haveria melhoria de bem-estar social (BOADWAY e BRUCE, 1984).

Para obter uma forma de comparar qualquer estado de bem-estar social ao longo do tempo para a mesma economia ou entre economias distintas, Bergerson e Samuelson estabeleceram as funções sociais de bem-estar na forma $W=f\left(U^{1}, \ldots, U^{n}\right)$, em que $U^{1}, \ldots, U^{n}$ são funções utilidades dos $n$ indivíduos que compõem o grupo social considerado (SILBERBERG e SUEN, 2001).

Em artigo publicado em 1963, Arrow demonstrou, por meio de sua teoria de escolha social, que não é possível construir uma função de bem-estar social sem violar uma das seguintes quatro propriedades "razoáveis" desejadas: a) a transitividade, que é a ordenação de preferências; b) o Critério de Pareto; c) a democracia ou domínio irrestrito, ou seja, que o procedimento para agregar utilidades individuais deve considerar qualquer ordenação de preferência de cada agente; e d) independência das alternativas irrelevantes, em que a ordenação de dois estados sociais deve depender exclusivamente da ordenação dos agentes (BOADWAY e BRUCE, 1984).

Diante disso, qualquer tentativa de constituir uma função de bem-estar social a partir das funções dos agentes será uma agregação ditatorial, pois irá violar pelo menos uma das propriedades colocadas anteriormente.

Por sua vez, trabalhos posteriores, entre eles os de Sen (1977, 1999), arguiram que as propriedades razoáveis definidas por Arrow não são tão "razoáveis", mas, sim, restritivas, porque anulam a possibilidade de ponderar o ganho dos agentes beneficiários contra a perda dos agentes prejudicados. Isso forneceu as bases 
para os resultados teóricos de que funções de ordenação social podem ser estabelecidas sem o critério ditatorial, pois as propriedades definidas por Arrow não são necessárias nos trabalhos empíricos.

Além disso, Sen considera que o desenvolvimento, em sua concepção mais ampla, não deve estar atrelado somente às questões puramente econômicas. Nesse sentido, o desenvolvimento deve estar vinculado com as liberdades reais com que as pessoas se defrontam, sendo estas os meios e não os fins. Para isso, Sen considera cinco liberdades fundamentais, as quais visam "contribuir para a capacidade geral de a pessoa viver mais livremente" (SEN, 2000; p. 55): (1) liberdades políticas; (2) facilidades econômicas; (3) oportunidades sociais; (4) garantias de transparência; e, (5) segurança protetora.

Na mesma linha de Sen, Sachs (2004) considera que o desenvolvimento é multidimensional e jamais poderá ser reduzido ou mesmo confundido com o crescimento da economia. Nesse aspecto, para alcançar o desenvolvimento, não basta que o crescimento econômico promova melhorias sociais, mas ele também deve estar atrelado à não degradação ambiental.

Apesar de toda a discussão acima, dentre as primeiras formas para se mensurar o bem-estar, a mais utilizada foi por meio do nível de renda, pois se assume que a renda é um indicador adequado para representar as condições de vida, a qual, por sua vez, tem uma estreita relação com o bem-estar. Hicks, Pigou e uma série de outros economistas utilizaram amplamente a renda nacional para mensurar o bem-estar (ISLAM e CLARKE, 2001), dadas a simplicidade e a facilidade de obtenção do valor da renda, e também pela dedução lógica e direta que se pode fazer: se a renda nacional está crescendo, o bem-estar da sociedade também está.

$\mathrm{Na}$ linha de raciocínio dos autores citados, o bem-estar de um grupo social pode ser mensurado simplesmente pela renda, o que gera o indicador condição de vida $(\mathrm{CV})$ e que pode ser representado como:

$$
C V=f(R N)
$$

Em que $R N$ é a renda nacional per capita.

No entanto, deve-se ter certo cuidado em analisar somente o nível de renda de uma sociedade, tendo em vista que ele mascara os aspectos distributivos, principalmente em países em desenvolvimento, a exemplo do Brasil.

Como ressaltam Ivanova, Arcelus e Srinivasan (1999, p. 159), "mesmo a renda nacional per capita sendo uma parte significativa da estratégia de desenvolvimento humano, ela por si só não consegue capturar todos os aspectos do desenvolvimento". Isso mostra que utilizar unicamente a renda per capita como um indicador de bem-estar pode não refletir as reais condições de desenvolvimento de um determinado grupo social.

Um indicador mais amplo para mensurar o bem-estar da sociedade é a qualidade de vida. Ela difere da condição de vida por incluir questões com grau de 
subjetividade maior, como a liberdade política, o relacionamento social e o meio ambiente. A essas questões, a literatura internacional trata como non-welfaristic issues (NW). Assim, a qualidade de vida $(\mathrm{QV})$ pode ser formulada como:

$$
Q V=z(C V, N W)
$$

Dessa forma, a melhora da qualidade de vida não depende apenas do aumento da renda. Por sua vez, mensurar características abstratas, como a liberdade política e o relacionamento social, é de grande dificuldade, tendo em vista que culturas distintas podem atribuir valores extremamente diferentes a essas características (WELZEL, INGLEHART e KLINGEMANN, 2003).

Uma forma ainda mais ampla para medir o bem-estar da sociedade, definido por Pearce e Nash (1981), engloba, além da geração de bens e serviços, sua distribuição e acesso aos serviços de saúde e educação. Na literatura específica, a isso se dá o nome de vetor de objetivos sociais desejáveis $(V)$. Desse modo, o bem-estar da sociedade $(B S)$, conforme definido pelos autores, pode ser definido matematicamente como:

$$
B S=\phi(C V, N W, V)
$$

Em que $C V$ é o indicador Condição de Vida, $N W$ é o indicador de non-welfaristic issues e $V$ é o vetor de objetos sociais desejáveis.

Em análises empíricas, uma forma reconhecidamente aceita de se mensurar o bem-estar de uma população é por meio do Índice de Desenvolvimento Humano (IDH).

Segundo Qizilbash (2002), o IDH é uma herança do esforço intelectual de Mahbub ul Haq; porém, foi graças ao Programa das Nações Unidas para o Desenvolvimento (PNUD), e com a intervenção direta do economista e prêmio Nobel Amartya Sen, que o índice ganhou notoriedade e passou a pertencer ao rol das estatísticas dos países.

Mahbud percebeu que os economistas estavam esquecendo do ser humano, quando tratavam do desenvolvimento. Assim, vislumbrou a necessidade de incorporar o progresso humano e a miséria no processo geral de desenvolvimento. Como o autor ressalta, "qualquer aproximação adequada poderia tratar o ser humano como meio e fim do desenvolvimento" (QIZILBASH, 2002, p. 2). A ideia do desenvolvimento humano envolve a melhoria da qualidade de vida, a qual não pode ser mensurada apenas pela análise do Produto Nacional Bruto.

Há dois conceitos de qualidade de vida: (1) o amplo, que exprime noções abstratas, como equidade e direitos humanos básicos, e (2) o restrito, que mede apenas o grau de acesso aos bens para atender às necessidades básicas. Ambos se sustentam, porque cada pessoa necessita de diferentes níveis de renda para ter o padrão de vida desejado (QIZILBASH, 2002).

Segundo Haddad e Bonelli (1998), o IDH é um índice sintético que engloba três dimensões: (a) o de Longevidade $(L)$ : medido pela esperança de vida ao 
nascer; (b) o nível de educação $(E)$ : medido pela combinação da taxa de alfabetização de adultos e da taxa de matrícula nos três níveis de ensino; e (c) o nível de renda $(Y)$ : medido pelo PIB per capita.

Para calcular o indicador de cada dimensão é necessário torná-los comparáveis. Isso é alcançado por meio de uma transformação dos valores individuais em uma escala de 0 a 1, a partir da seguinte expressão:

$$
I_{i j}=\frac{\left(V_{i j}-\operatorname{Min} V_{i j}\right)}{\left(\operatorname{Max} V_{i}-\operatorname{Min} V_{i}\right)}
$$

Em que:

$V_{i j}=$ valor do componente $i$ no local $j$

$\operatorname{Max} V_{i}=$ valor máximo do componente $i$ no local $j$

$\operatorname{Min} V_{i}=$ valor mínimo do componente $i$ no local $j$

Por sua vez, o IDH é obtido por meio da média aritmética dos índices referentes às três dimensões:

$$
I D H=\frac{1}{3}(L+E+Y)
$$

Segundo Ianova, Arcelus e Srinivasan (1999), o IDH não foi elaborado para prever, mas, sim, para medir o nível de desenvolvimento humano entre locais distintos, devendo permitir sua comparação ao longo do tempo para se ter clareza de sua melhoria ou de sua deterioração.

\section{Metodologia e dados utilizados}

Esta seção está dividida em três partes. Inicialmente, ressalta-se a relação entre desmatamento e geração de renda e desta última com o IDH, destacando de que modo uma possível redução da área agrícola (para reposição da cobertura florestal nativa) reduziria a renda e, por conseguinte, o IDH. O item 4.2 discorre sobre os dados utilizados e o item 4.3 expõe os procedimentos econométricos aplicados.

\subsection{Relação entre desmatamento, renda e bem-estar}

O desmatamento ocorre, entre outros motivos, para disponibilizar o fator de produção terra para outro uso, como para a produção agropecuária. Essa última gera o PIB agropecuário, que somado com o PIB proveniente de outras atividades da economia, o industrial e o de serviços, geram o PIB total da economia, o qual, dividido pela população, resulta no PIB per capita. Esse valor combinado com a esperança de vida (longevidade) e com o nível de educação define o nível de bem-estar de uma sociedade. O fluxograma 1 evidencia essas relações. 
Fluxograma 1. Relação entre desmatamento e bem-estar.

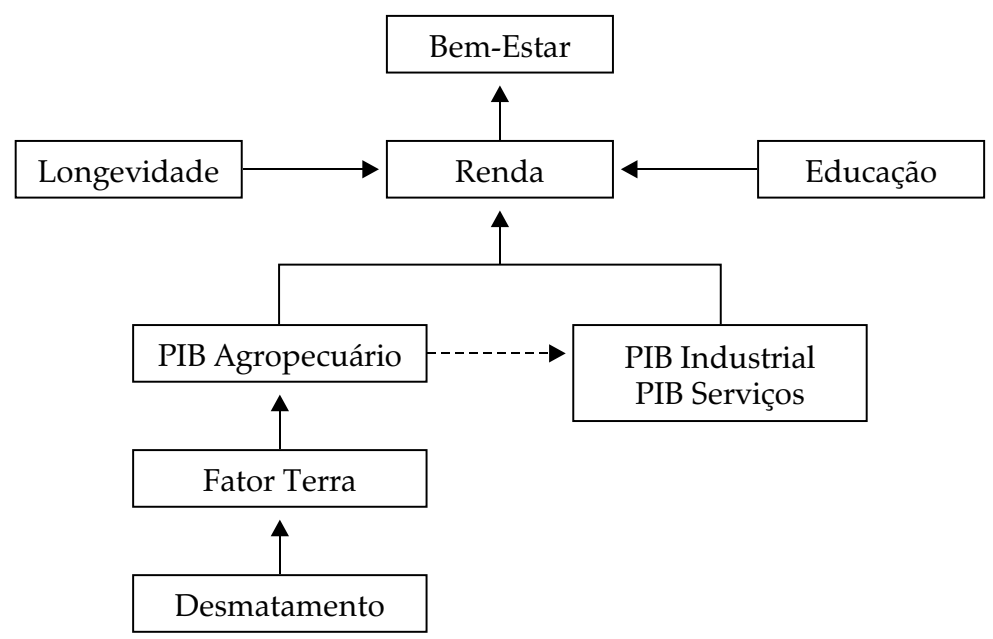

O raciocínio revelado no fluxograma 1 pode ocorrer em escala municipal, estadual ou nacional. Em escala municipal, pode-se definir o IDH-M, o qual é calculado pela seguinte fórmula:

$$
I D H_{M}=\frac{(I Y+I E+I L)}{3}
$$

Em que $I Y, I E$ e IL são, respectivamente, os índices de renda, educação e longevidade ${ }^{3}$. O índice renda (IY) é calculado por meio de uma função logarítmica, devido ao pressuposto de que a contribuição da renda para o bem-estar assume retornos decrescentes. A equação de cálculo do IY para o Brasil é:

$$
I Y=\frac{\ln (\bar{Y})-\ln (3,90)}{\ln (1559,24)-\ln (3,90)}
$$

A renda per capita é $\bar{Y}=\left(Y_{a}+Y_{i}+Y_{s}\right) / P$, em que $Y_{a}, Y_{i}$, $Y_{s}$ e $P$ são, respectivamente, o PIB agropecuário, o PIB industrial, o PIB de serviços e a população. Os valores inclusos na fórmula 7, R $\$ 1559,24$ e R \$ 3,90, são os valores limites estabelecidos pelo PNUD ${ }^{4}$ para o cálculo do índice de renda no Brasil e que são adotados também neste estudo.

${ }^{3}$ OÍndice Longevidade é calculado por: $I L=\left(V_{i}-25\right) /(85-25)$, em que $V_{i}$ é a esperança de vida ao nascer e os valores 25 e 85 são as idades mínima e máxima que devem ser consideradas no índice de longevidade. O Índice Educação é calculado por: $I E=\left(2 I A_{i}+I M_{i}\right) / 3$, em que $I A_{i}$ é o índice da taxa de alfabetização de adultos e $I M_{i}$ é o índice da taxa de matrículas.

${ }^{4}$ Ver Atlas do Desenvolvimento Humano no Brasil. 
O segundo objetivo específico do trabalho é verificar o quanto o nível de bem-estar, mensurado pelo IDH-M, é afetado caso haja restrição no uso da terra. Para tanto, é necessário:

1. identificar, inicialmente, a participação da terra no PIB agropecuário, o que é feito através da estimativa de uma função de produção;

2. verificar o quanto o PIB da agropecuária diminui se houver restrição no uso da terra. Para tanto, utiliza-se um modelo não linear de otimização e os resultados da função de produção estimada;

3. calcular o quanto reduz o PIB do agronegócio a partir da diminuição do PIB da agropecuária. A redução do PIB do agronegócio é a redução do PIB total quando da restrição do uso da terra para a agropecuária; e

4. com o novo valor do índice de renda, quando da restrição do uso da terra para a agropecuária, calcular o novo IDH-M.

A função de produção permite mensurar a quantidade de fatores de produção (entre os quais a terra) necessária para obter um determinado volume de produto.

De maneira geral, uma função de produção é caracterizada por:

$$
Y=f(K, L, T)
$$

Em que $Y$ é o produto e $K, L e T$ são, respectivamente, as quantidades dos fatores de produção capital, trabalho e terra.

Adotando o formato Cobb-Douglas para a função de produção, tem-se:

$$
Y=A K^{\alpha} L^{\beta} T^{1-\alpha-\beta}
$$

Em que A é a tecnologia e $K, L$ e $T$ são os fatores de produção capital, trabalho e terra, respectivamente. Já $\alpha$ e $\beta$ são os parâmetros que indicam o grau de substituição entre os fatores. Também se assume que $\alpha>0, \beta>0 \mathrm{e}(\alpha+\beta)<1$. A equação (9) será estimada em duas escalas de análise, utilizando dados em nível municipal ${ }^{5}$ : para a Amazônia como um todo e para cada um dos estados que a compóem.

Após calcular os parâmetros da função de produção para cada estado e assumindo que os agentes são racionais e, portanto, otimizadores, pode-se avaliar os impactos sobre a renda de uma redução da área utilizada pela atividade agropecuária. Para se determinar o quanto de terra deveria ser retirado da atividade agropecuária, considerou-se a legislação florestal existente, a área total dos estabelecimentos agropecuários e o quanto eles têm de florestas. Assim, para cada estado, calculou-se o quanto estaria faltando de florestas dentro dos estabelecimentos agropecuários e o quanto, assim, deveria ser retirado da produção agropecuária. Dessa forma, está-se diante de um problema de otimização condicionada, ou seja, os agentes otimizam o produto agropecuário levando em consideração a restrição do fator terra. Tem-se o seguinte modelo de otimização:

\footnotetext{
${ }^{5}$ A região tinha 625 municípios à época do Censo Agropecuário de 1995.
} 
Maximizar: $Y=A K^{\alpha} L^{\beta} T^{1-\alpha-\beta}$

sujeito a: $\quad T \leq T_{0}$

$$
K, L, T \geq 0
$$

Em que $T_{0}$ é a máxima quantidade possível do fator terra que pode ser utilizada na agropecuária.

A solução do problema de otimização com restrição de desigualdade é obtida por meio da formulação de Kurn-Tucker. Inicialmente, a função de Lagrange $(\Phi)$ é:

$$
\Phi=A K^{\alpha} L^{\beta} T^{1-\alpha-\beta}+\lambda\left(T_{0}-T\right)
$$

Em que $\lambda$ é o multiplicador de Lagrange. Vale ressaltar que a diferença $T_{0}-T$ é sempre não negativa. As condições de Kurn-Tucker para a equação (11) são:

$$
\begin{array}{lll}
\Phi_{K}=\frac{\partial \Phi}{\partial K}=\alpha A K^{\alpha-1} L^{\beta} T^{1-\alpha-\beta} \leq 0 & K \geq 0 & \text { e } \quad \Phi_{K} K=0 \\
\Phi_{L}=\frac{\partial \Phi}{\partial L}=\beta A K^{\alpha} L^{\beta-1} T^{1-\alpha-\beta} \leq 0 & L \geq 0 & \text { e } \quad \Phi_{L} L=0 \\
\Phi_{T}=\frac{\partial \Phi}{\partial T}=(1-\alpha-\beta) A K^{\alpha} L^{\beta} T^{1-\alpha-\beta}+\lambda \leq 0 & T \geq 0 & \text { e } \quad \Phi_{T} T=0 \\
\Phi_{\lambda}=\frac{\partial \Phi}{\partial \lambda}=T_{0}-T \leq 0 & \lambda \geq 0 & \text { e } \quad \Phi_{\lambda} \lambda=0
\end{array}
$$

O conjunto das inequações de (12) a (15) mostra a condição de Kurn-Tucker para o problema de otimização com restrição de desigualdade, ou seja, aponta a condição necessária de primeira ordem para atingir um ponto de máximo, tendo como restrições a quantidade de terras utilizada na produção agropecuária, a não negatividade de todos os fatores de produção considerados e o multiplicador de Lagrange.

Por meio da função de produção, é possível simular diferentes quantidades de terra utilizada na produção agropecuária, o que irá resultar em diferentes valores para o PIB agropecuário. No entanto, o PIB agropecuário é apenas uma parcela do PIB total, e é este último que determina o índice de renda (um dos três componentes do IDH-M). Dessa forma, faz-se necessário conhecer a participação do PIB agropecuário no PIB total. E essa participação é dada pelo PIB do agronegócio, o qual engloba, além da produção agrícola propriamente dita, os setores de insumos, de processamento industrial e de distribuição e demais serviços (GUILHOTO, 2004). A partir de coeficientes da relação PIBagronegócio/PIBagropecuário, pode-se calcular os novos valores do PIB total segundo os novos valores do PIB da agropecuária. Por exemplo, se em um estado particular o PIB da agropecuária cai $R \$ 1,00$, e a relação PIBagronegócio/PIBagropecuário é 3 , haverá uma redução de $R \$ 3,00$ no PIB total do estado. 
Com o novo valor do PIB do estado, em termos per capita, é possível calcular o índice de renda por meio da equação (7). Combinando o índice da renda com os índices de longevidade e educação, calcula-se o novo IDH-M. Vale ressaltar que se assume a interdependência entre os três setores da economia (agropecuária, indústria e serviços) e a independência entre os índices que compõem o IDH-M. Ou seja, uma variação do PIB do setor agropecuário interfere no PIB dos demais setores da economia. Por sua vez, qualquer variação no índice renda não afeta os índices de educação e longevidade.

\subsection{Dados utilizados}

Do censo agropecuário de 1995 foram extraídas as parcelas de áreas utilizadas na produção agropecuária, o número de trabalhadores e as classes de potência dos tratores. A quantidade de terra utilizada na produção agropecuária (a variável $T$ da equação 9) é uma proxy da área desmatada. O número de trabalhadores fornece o fator trabalho (variável $L$ ). O capital utilizado na produção agropecuária é mensurado por meio de uma proxy, a quantidade de tratores (variável $K$ ), medida pela potência (em cavalo vapor) disponível em cada município. Os dados do censo agropecuário de 1995 mostram, para cada município, a quantidade de tratores em cada uma das seguintes classes de potência: menor que $10 \mathrm{cv}$; de $10 \mathrm{cv}$ a $20 \mathrm{cv}$; de $20 \mathrm{cv}$ a $50 \mathrm{cv}$; de $50 \mathrm{cv}$ a $100 \mathrm{cv}$ e maior que $100 \mathrm{cv}$. A potência total foi estimada pelo somatório dos valores médios de cada classe, multiplicado pelo número de tratores existentes. A isso se soma o produto do número de tratores acima de $100 \mathrm{cv}$ multiplicado por 100. Na impossibilidade de se determinar um valor para a última classe, assumiu que todos os tratores acima de $100 \mathrm{cv}$ têm $100 \mathrm{cv}$.

Os valores do Produto Interno Bruto (PIB) dos municípios e do PIB Agrícola foram coletados no Ipeadata. O Ipeatada disponibiliza os dados já deflacionados, ou seja, a preços constantes.

Os coeficientes da relação PIBagronegócio/PIBagropecuária foram obtidos no trabalho elaborado por Guilhoto (2004).

Os dados referentes ao Índice do Desenvolvimento Humano Municipal (IDH-M) foram obtidos no Atlas do Desenvolvimento Humano no Brasil, um banco de dados eletrônico com informações socioeconômicas sobre os 5.507 municípios do País, os 26 estados e o Distrito Federal.

Pela característica do IDH-M, os dados necessários para sua construção são de natureza bastante específica - o levantamento só se dá nos períodos de realização dos censos populacionais. Como, no Brasil, os censos demográficos são realizados decenalmente, exceção para 1991, é possível construir o IDH-M somente para tais anos. No entanto, os censos agropecuários são realizados também decenalmente, mas em anos não necessariamente iguais aos do censo demográfico. Dessa forma, obteve-se o IDH-M para 1995 por meio do IDH-M de 1991 e 2000, bem como os subíndices educação e longevidade. Para tal fim, foi utilizado o método de Interpolação de Lagrange. 
O método de Interpolação de Lagrange baseia-se na construção de um polinômio $p_{n}(x)$ de grau menor ou igual a $n$, que interpola a função desejada $f$, porém desconhecida, nos pontos $x_{0}, x_{1}, \ldots, x_{n}$. Pode-se representar $p_{n}(x)$ como $p_{n}(x)=y_{0} L_{0}(x)+y_{1} L_{1}(x)+\ldots+y_{n} L_{n}(x)$, em que os polinômios $L_{k}(x)$ são de grau $n$. Para cada $i$, quer se achar a condição $p_{n}\left(x_{i}\right)=y_{i}$ que satisfaça $p_{n}\left(x_{i}\right)=y_{0} L_{0}\left(x_{i}\right)+y_{1} L_{1}\left(x_{i}\right)+\ldots+y_{n} L_{n}\left(x_{i}\right)=y_{i}$. Resumidamente, pode-se escrever o polinômio da interpolação de Lagrange da seguinte forma:

$$
P_{n}(x)=\sum_{i=0}^{n} y_{i} \prod_{\substack{j=0 \\ j \neq i}}^{n} \frac{\left(x-x_{j}\right)}{\left(x_{i}-x_{j}\right)}
$$

Com base no polinômio calculado para cada município, calculou-se o IDH-M e os seus subíndices para o ano de 1995, levando em consideração o IDH-M de 1991 e 2000. Como só existem dois valores, o polinômio se torna de grau um, o qual foi calculado para cada município analisado.

\subsection{Procedimentos econométricos utilizados}

Assumindo a função de produção Cobb-Douglas para três fatores de produção: Capital, Trabalho e Terra $(K, L$ e $T)$, tem-se:

$$
Y_{i}=A K_{i}^{\alpha} L_{i}^{\beta} T_{i}^{1-\alpha-\beta}+e_{i}
$$

Em que A, $\alpha$ e $\beta$ são os parâmetros da função e $e_{i}$ é o erro aleatório, em que $E[e]=0$ e $E\left[e^{\prime} e\right]=\sigma^{2}$. O subscrito $i$ representa o município analisado.

Como a função (17) é não linear, o procedimento para sua estimação é por meio do algoritmo de Gauss-Newton ${ }^{6}$, o qual é dado por:

$$
\beta_{n+1}=\beta_{n}+\left[Z\left(\beta_{n}\right)^{\prime} Z\left(\beta_{n}\right)\right]^{-1} Z\left(\beta_{n}\right)^{\prime}\left[Y-f\left(X, \beta_{n}\right)\right]
$$

Em que $\beta^{\prime}=(A, \alpha, \beta)$ é o vetor linha dos parâmetros; $Z\left(\beta_{n}\right)=\frac{\partial f(X, \beta)}{\partial \beta^{\prime}}$ é a matriz das derivadas primeiras da função de produção em relação aos seus parâmetros; e $X^{\prime}=\left(K_{i}, L_{i}, T_{i}\right)$ é o vetor linha das variáveis empregadas na função de produção.

A derivada da função Cobb-Douglas em relação aos seus parâmetros (o gradiente da função) é dada por:

$$
\begin{aligned}
& Z\left(\beta_{n}\right)=\frac{\partial f(X, \beta)}{\partial \beta^{\prime}}=\left[\frac{\partial f(X, \beta)}{\partial A}, \frac{\partial f(X, \beta)}{\partial \alpha}, \frac{\partial f(X, \beta)}{\partial \beta}\right]= \\
& {\left[K_{i}^{\alpha} L_{i}^{\beta} T_{i}^{1-\beta-\alpha}, A K_{i}^{\alpha} L_{i}^{\beta} T_{i}^{1-\beta-\alpha}\left(\ln K_{i}-\ln T_{i}\right), A K_{i}^{\alpha} L_{i}^{\beta} T_{i}^{1-\beta-\alpha}\left(\ln L_{i}-\ln T_{i}\right)\right]}
\end{aligned}
$$

${ }^{6}$ Para um melhor entendimento do processo de estimação de funções não lineares, consultar JUDGE et al. (1988). 
Fazendo $\Psi_{i}=K_{i}^{\alpha} L_{i}^{\beta} T_{i}^{1-\beta-\alpha}$, tem-se:

$$
Z\left(\beta_{n}\right)=\frac{\partial f(X, \beta)}{\partial \beta}=\left[\Psi_{i}, A \Psi_{i}\left(\ln K_{i}-\ln T_{i}\right), A \Psi_{i}\left(\ln L_{i}-\ln T_{i}\right)\right]
$$

Como pode ser visto em (18), é necessário obter a matriz $(3 \times 3)$ :

$$
\begin{aligned}
& {\left[Z\left(\beta_{n}\right)^{\prime} Z\left(\beta_{n}\right)\right]=} \\
& =\left[\begin{array}{ccc}
\sum_{i=1}^{n} \Psi_{i}^{2} & A \sum_{i=1}^{n} \Psi_{i}^{2}\left(\ln K_{i}-\ln T_{i}\right) & A \sum_{i=1}^{n} \Psi_{i}^{2}\left(\ln L_{i}-\ln T_{i}\right) \\
A \sum_{i=1}^{n} \Psi_{i}^{2}\left(\ln K_{i}-\ln T_{i}\right) & A^{2} \sum_{i=1}^{n} \Psi_{i}^{2}\left(\ln K_{i}-\ln T_{i}\right)^{2} & A^{2} \sum_{i=1}^{n} \Psi_{i}^{2}\left(\ln K_{i}-\ln T_{i}\right)\left(\ln L_{i}-\ln T_{i}\right) \\
A \sum_{i=1}^{n} \Psi_{i}^{2}\left(\ln L_{i}-\ln T_{i}\right) & A^{2} \sum_{i=1}^{n} \Psi_{i}^{2}\left(\ln K_{i}-\ln T_{i}\right)\left(\ln L_{i}-\ln T_{i}\right) & A^{2} \sum_{i=1}^{n} \Psi_{i}^{2}\left(\ln L_{i}-\ln T_{i}\right)^{2}
\end{array}\right]
\end{aligned}
$$

Além da matriz, é necessário também obter o vetor $(3 \times 1)$ :

$$
Z\left(\beta_{n}\right)^{\prime}\left[Y-f\left(X, \beta_{n}\right)\right]=\left[\begin{array}{c}
\sum_{i=1}^{n} \Psi_{i}\left(Y_{i}-A \Psi_{i}\right) \\
A \sum_{i=1}^{n} \Psi_{i}\left(\ln K_{i}-\ln T_{i}\right)\left(Y_{i}-A \Psi_{i}\right) \\
A \sum_{i=1}^{n} \Psi_{i}\left(\ln L_{i}-\ln T_{i}\right)\left(Y_{i}-A \Psi_{i}\right)
\end{array}\right]
$$

O algoritmo de Gauss-Newton (equação 18) tem início por meio da atribuição de valores arbitrários para cada um dos parâmetros $\mathrm{A}, \alpha$ e $\beta$. $\mathrm{O}$ resultado da operação é um novo conjunto de parâmetros, os quais são atribuídos novamente ao algoritmo. Esse processo é denominado iteração e finaliza quando o resultado do parâmetro obtido é igual ao atribuído ao algoritmo.

Há algumas limitações em relação aos aspectos metodológicos aqui adotados, principalmente quanto ao cálculo do IDH-M. Como visto anteriormente, o IDH-M é composto pelos índices de educação, longevidade e renda. No presente trabalho, foi utilizado o PIB municipal para o cálculo do índice de renda. Como o PIB é a remuneração dos fatores de produção utilizados, pode ocorrer, no caso dos municípios da Amazônia, que uma parcela sirva para remunerar agentes não residentes no município, contribuindo, dessa forma, para melhorar o nível de bem-estar fora da própria Amazônia. Muitos municípios recebem transferências do governo, as quais não estão diretamente relacionadas às atividades de dentro do município e podem elevar o padrão de consumo da população local, gerando, assim, um melhor nível de bem-estar. Além disso, embora existam escolas e planos de saúde privados, dos quais para se ter acesso há a necessidade de renda, a maior parte dos serviços de educação e de saúde é proveniente do governo, o que garante um padrão mínimo de bem-estar da população de cada local, independente da variável renda. 


\section{Resultados}

A estimativa realizada da função de produção (ver tabela 1) mostra que, para a Amazônia como um todo, os coeficientes são estatisticamente significativos para os fatores de produção capital e trabalho (ambos a 1\%). No entanto, o coeficiente associado ao fator terra não é estatisticamente significativo, além de o seu sinal contrariar o esperado pelo modelo, ou seja, o aumento desse fator gera diminuição da renda agropecuária (ver tabela 1). O ajustamento da regressão foi satisfatório, mas não alto $\left(\mathrm{R}^{2}=0,6801\right)$. Isso pode estar relacionado às distintas características naturais entre os municípios da região quanto à topografia e à fertilidade do solo, por exemplo. Além disso, é importante ressaltar que a ocupação da região ocorreu de forma extensiva e que coexistem diferentes estruturas de produção agropecuária, da rudimentar à avançada tecnologicamente.

Tabela 1. Estimativa dos coeficientes da função de produção Cobb-Douglas para a Amazônia e seus estados.

\begin{tabular}{|c|c|c|c|c|c|c|c|}
\hline \multirow{2}{*}{ Estado } & \multirow[b]{2}{*}{ Constante (A) } & \multicolumn{2}{|c|}{ Fatores de Produção } & \multicolumn{4}{|c|}{ Estatísticas } \\
\hline & & Terra (T) & Capital (K) & Trabalho (L) & $\mathbf{R}^{2}$ & Observ. & $\mathbf{F}$ \\
\hline Amazônia & $\begin{array}{c}3,914615^{*} \\
(9,95)\end{array}$ & $\begin{array}{c}-0,0355511 \\
(-0,90)\end{array}$ & $\begin{array}{c}0,4868481^{*} \\
(14,94)\end{array}$ & $\begin{array}{c}0,5487005^{*} \\
(30,58)\end{array}$ & 0,6801 & 625 & 443,87 \\
\hline Acre & $\begin{array}{c}6,343892^{* * *} \\
(1,89) \\
\end{array}$ & $\begin{array}{c}-0,315586 \\
(-1,66) \\
\end{array}$ & $\begin{array}{c}0,1987377 \\
(1,55) \\
\end{array}$ & $\begin{array}{c}1,1168480^{*} \\
(12,47) \\
\end{array}$ & 0,9041 & 22 & 70,15 \\
\hline Amapá & $\begin{array}{c}11,63675^{*} \\
(7,78) \\
\end{array}$ & $\begin{array}{c}0,2545576^{* * *} \\
(1,97) \\
\end{array}$ & $\begin{array}{c}0,527744^{*} \\
(11,49) \\
\end{array}$ & $\begin{array}{c}0,2176983^{* * *} \\
(1,74)\end{array}$ & 0,9781 & 15 & 224,63 \\
\hline Amazonas & $\begin{array}{c}0,2607558 \\
(0,31) \\
\end{array}$ & $\begin{array}{c}0,3874839 \\
(0) \\
\end{array}$ & $\begin{array}{c}3,69 \mathrm{E}-10 \\
(0)\end{array}$ & $\begin{array}{c}0,6125161 \\
(0,49) \\
\end{array}$ & 0,0544 & 62 & 2,19 \\
\hline Maranhão & $\begin{array}{c}1,168268^{*} \\
(2,44)\end{array}$ & $\begin{array}{c}0,2495995^{*} \\
(5,51)\end{array}$ & $\begin{array}{c}0,0795139 * * \\
(8,66)\end{array}$ & $\begin{array}{c}0,6708859^{*} \\
(16,37)\end{array}$ & 0,8824 & 113 & 283,64 \\
\hline Mato Grosso & $\begin{array}{c}1,988337^{* *} \\
(10,26) \\
\end{array}$ & $\begin{array}{c}-0,1618186 \\
(-1,08) \\
\end{array}$ & $\begin{array}{c}0,9771264^{*} \\
(10,26) \\
\end{array}$ & $\begin{array}{c}0,1846921^{* *} \\
(2,06)\end{array}$ & 0,8237 & 116 & 181,62 \\
\hline Pará & $\begin{array}{c}2,200141^{*} \\
(9,45)\end{array}$ & $\begin{array}{c}0,0733391^{* * *} \\
(1,86)\end{array}$ & $\begin{array}{c}0,0197835^{* * *} \\
(1,59) \\
\end{array}$ & $\begin{array}{c}0,9068776^{*} \\
(26,09) \\
\end{array}$ & 0,8282 & 127 & 205,11 \\
\hline Rondônia & $\begin{array}{c}1,873102^{* *} \\
(2,44)\end{array}$ & $\begin{array}{c}0,1658774 \\
(1,04) \\
\end{array}$ & $\begin{array}{c}0,2308906^{*} \\
(2,81) \\
\end{array}$ & $\begin{array}{c}0,603232^{*} \\
(5,11) \\
\end{array}$ & 0,9232 & 39 & 157,22 \\
\hline Roraima & $\begin{array}{c}0,9581786 \\
(1,28) \\
\end{array}$ & $\begin{array}{c}0,5248557^{* * *} \\
(1,99)\end{array}$ & $\begin{array}{c}0,0484265 \\
(0,26) \\
\end{array}$ & $\begin{array}{c}0,4267177^{* * *} \\
(2,45)\end{array}$ & 0,9117 & 8 & 28,54 \\
\hline Tocantins & $\begin{array}{c}56,17097^{* *} \\
(2,02)\end{array}$ & $\begin{array}{c}-1,435986^{*} \\
(-6,47)\end{array}$ & $\begin{array}{c}1,777781^{*} \\
(8,54)\end{array}$ & $\begin{array}{c}0,6582077^{*} \\
(5,5)\end{array}$ & 0,6723 & 123 & 85,11 \\
\hline
\end{tabular}

Fonte: Resultados da pesquisa.

Nota: entre parênteses está a estatística $t$ de Student, sendo que * indica o coeficiente ser significativo a $1 \%$; ${ }^{*}$, significativo a $5 \%, \mathrm{e}^{* * *}$, significativo a $10 \%$ 
Para o estado do Acre, o único fator de produção estatisticamente significativo na função de produção é o trabalho. O Amapá apresentou todos os coeficientes associados aos fatores de produção estatisticamente significativos, com os seus sinais de acordo com o esperado. Para o estado do Amazonas, os coeficientes estimados não são estatisticamente significativos a $10 \%$. Todos os coeficientes para o estado do Maranhão se mostraram estatisticamente significativos e os seus sinais de acordo com o esperado. No estado de Mato Grosso, o coeficiente associado ao fator terra não se mostrou estatisticamente significativo e, além disso, seu sinal é negativo, contrariando as pressuposições do modelo. Os coeficientes para terra, trabalho e capital são estatisticamente significativos para o Pará e têm os sinais esperados. Para o estado de Rondônia, o coeficiente associado à terra não é significativo estatisticamente, apesar de ter o sinal esperado, e os demais o são e com os sinais esperados. Em Roraima, os coeficientes associados à terra e ao trabalho são estatisticamente significativos e com os sinais esperados, enquanto o coeficiente associado ao capital não é estatisticamente significativo, apesar de ter o sinal esperado. E, finalmente, no estado do Tocantins, todos os coeficientes são estatisticamente significativos, embora o associado à terra apresente sinal negativo, o que contraria as pressuposições do modelo.

As funções de produção para cada estado da Amazônia não apresentam um comportamento homogêneo. Isso pode estar relacionado à dimensão da região em análise e também às técnicas produtivas exercidas, as quais combinam de forma bastante diferenciada os fatores de produção.

Para determinar a redução da quantidade de terra usada nas propriedades rurais, levou-se em consideração: (1) a atual legislação florestal, que determina a área de reserva legal em no mínimo $80 \%$ da área total de cada propriedade localizada na Amazônia Legal e que tenha cobertura florestal ${ }^{7}$ (Medida Provisória 2.166-67 de 24/08/2001); (2) a quantidade de terras sem cobertura florestal na forma de matas naturais ou plantadas dentro de cada estabelecimento agropecuário situado na Amazônia Legal ${ }^{8}$. De acordo com a tabela 2, e nas condições da legislação vigente, pode-se verificar que os estabelecimentos agropecuários em todos os estados excedem o uso de terras

\footnotetext{
${ }^{7}$ O limite mínimo de $80 \%$ (definido pela primeira vez pela Medida Provisória 1.511 de 25/07/1996) da área total a ser mantida como reserva legal é válida atualmente para áreas cobertas com florestas nativas. As áreas cobertas com cerrado devem manter o limite de $35 \%$ da área total como reserva legal, e as áreas com campo têm o limite mínimo de $20 \%$. Devidoà falta de dados para fazer essa segmentação, o presente artigo faz a simplificação de adotar o limite de $80 \%$ e, com isso, superestima o montante necessário a ser reduzido de terra.

${ }^{8}$ A exigência legal é que a reserva legal seja feita no imóvel rural, o que se viabiliza se cada estabelecimento agropecuário a tiver. Como não é possível separar as florestas plantadas em exóticas e nativas, bem como em homogêneas e heterogêneas, considerou-se toda a cobertura florestal existente dentro dos estabelecimentos agropecuários.
} 
permitido, ou seja, a quantidade de matas está aquém do estipulado legalmente. Dessa forma, há a necessidade de reduzir a quantidade de terras utilizadas dentro dos estabelecimentos agropecuários para aumentar a área com matas. $\mathrm{O}$ estado que mais deve diminuir o uso de terra nos estabelecimentos agropecuários é Tocantins, seguido de Roraima, Mato Grosso e Maranhão.

Tabela 2. Área dos estabelecimentos agropecuários segundo a utilização das terras e redução da área utilizada para atender às exigências legais.

\begin{tabular}{|c|c|c|c|c|c|c|c|}
\hline \multirow[b]{2}{*}{ Estados } & \multicolumn{6}{|c|}{ Área dos estabelecimentos } & \multirow{2}{*}{$\begin{array}{c}\text { Percentagem } \\
\text { de redução da } \\
\text { área utilizada } \\
\text { na produção } \\
\text { agropecuária } \\
\text { para ter } 80 \% \\
\text { de mata no } \\
\text { estabelecimento* }\end{array}$} \\
\hline & $\begin{array}{l}\text { Utilizada na } \\
\text { produção } \\
\text { agropecuária }\end{array}$ & $\%$ & $\begin{array}{l}\text { Com matas } \\
\text { naturais e } \\
\text { plantadas }\end{array}$ & $\%$ & $\begin{array}{c}\text { Com terras } \\
\text { produtivas não } \\
\text { utilizadas e } \\
\text { terras } \\
\text { inaproveitáveis }\end{array}$ & $\%$ & \\
\hline Acre & 690.152 & 21,68 & 2.338 .412 & 73,46 & 154.501 & 4,85 & 7,76 \\
\hline Amapá & 264.831 & 37,83 & 374.626 & 53,51 & 60.590 & 8,66 & 47,13 \\
\hline Amazonas & 764.274 & 23 & 2.145 .316 & 64,57 & 412.976 & 12,43 & 13,05 \\
\hline Maranhão & 6.132 .379 & 48,82 & 2.875 .775 & 22,9 & 3.552 .538 & 28,28 & 59,03 \\
\hline Mato Grosso & 24.403 .806 & 48,96 & 21.543 .594 & 43,23 & 3.892 .231 & 7,81 & 59,15 \\
\hline Pará & 8.264 .082 & 36,7 & 11.707 .425 & 51,99 & 2.548 .722 & 11,32 & 45,50 \\
\hline Rondônia & 3.354 .377 & 37,73 & 5.131 .460 & 57,72 & 404.603 & 4,55 & 46,99 \\
\hline Roraima & 1.675 .577 & 56,29 & 1.023 .388 & 34,38 & 277.852 & 9,33 & 64,47 \\
\hline Tocantins & 11.345 .384 & 67,67 & 3.036 .006 & 18,11 & 2.384 .326 & 14,22 & 70,44 \\
\hline
\end{tabular}

Fonte: IBGE (1995).

* Por exemplo, no caso do Acre, essa percentagem significa que a nova área da agropecuária deve ser 92,24\% da original, ou seja, 7,76\% inferior à original.

A função de produção se ajustou sem qualquer restrição somente a três estados (Amapá, Pará e Maranhão), conforme pode ser observado na tabela 1. Mesmo apresentando um dos coeficientes não significativo estatisticamente, as funções de produção dos estados de Rondônia e Roraima estão com os sinais dos coeficientes de acordo com o esperado. Dessa forma, calcula-se a otimização do produto agropecuário, levando em consideração a restrição do fator terra (tabela 2) para esses estados, o que pode ser verificado na tabela 3.

A segunda coluna da tabela 3 mostra o produto (PIB) oficial da agropecuária. A terceira coluna fornece as estimativas do PIB agropecuário utilizando a totalidade de terra em uso em 1995, o que serve de comparação com os demais valores quando há restrições na quantidade de terra utilizada. E a quarta coluna mostra a dimensão do PIB agropecuário quando a quantidade de terra permitida para o uso se ajusta à legislação florestal. Nesse cálculo, foi considerada a mesma redução do fator terra nos fatores trabalho e capital. 
Tabela 3. Valor do PIB agropecuário quando o uso da terra é restrito (R\$).

\begin{tabular}{lccc}
\hline Estado & PIB Oficial & $\begin{array}{c}\text { PIB estimado } \\
\text { com 100\% da } \\
\text { terra utilizada }\end{array}$ & $\begin{array}{c}\text { PIB estimado para } \\
\text { que 80\% da área das } \\
\text { propriedades seja } \\
\text { coberta com matas* }\end{array}$ \\
\hline Amapá & 127.851 .400 & 177.836 .200 & 94.017 .460 \\
Maranhão & 1.381 .605 .000 & 1.416 .081 .000 & 568.191 .200 \\
Pará & 2.256 .748 .000 & 2.193 .323 .000 & 1.195 .393 .000 \\
Rondônia & 641.476 .000 & 707.018 .400 & 374.776 .300 \\
Roraima & 115.950 .000 & 121.330 .800 & 43.111 .060 \\
\hline
\end{tabular}

Fonte: Resultados da pesquisa.

Nota: *os cálculos foram realizados por meio do software Lingo, versão 11.0. Considerou-se que os fatores trabalho e capital tenham a mesma redução que o fator terra.

Com exceção do estado do Amapá, em que o valor calculado para o PIB (terceira coluna) é bastante discrepante do valor oficial (segunda coluna), o ajustamento da função de produção para o restante dos estados gera resultados próximos dos valores oficiais.

Para o estado do Amapá, a redução da área utilizada resultaria em uma diminuição do PIB agropecuário de $\mathrm{R} \$ 177.836 .200,00$ para $\mathrm{R}$ \$94.017.460,00, ou seja, ocorreria uma queda do PIB agropecuário de 47,13\%. Com a restrição no uso da terra, o PIB agropecuário do Maranhão recuaria de $\mathrm{R} \$ 1.416 .081 .000,00$ para $\mathrm{R} \$ 568.191 .200,00$, o que representa uma queda de 59,88\%. No estado do Pará, o PIB agropecuário reduziria 45,5\%, caindo de $\mathrm{R} \$ 2.193 .323 .000,00$ para $\mathrm{R} \$ 1.195 .393 .000,00$. O PIB agropecuário no estado de Rondônia passaria de $\mathrm{R} \$ 707.018 .400,00$ para $\mathrm{R} \$ 374.776 .300,00$, representando uma diminuição de 46,99\%. E para o estado de Roraima, o PIB agropecuário cairia de R\$ $121.330 .800,00$ para $\mathrm{R} \$ 43.111 .060,00$, redução de $64,47 \%$, sendo a maior queda percentual entre todos os estados analisados. Já em valores absolutos, a baixa mais expressiva ocorreria no estado do Pará, o qual perderia $\mathrm{R} \$ 997.930 .000,00$ em seu PIB agropecuário, considerando o ano de 1995, para repor as florestas dentro dos estabelecimentos agropecuários aos níveis exigidos pela legislação florestal.

$\mathrm{Na}$ tabela 4 pode-se observar, nos estados selecionados, a magnitude da redução do PIB da agropecuária quando são adotadas restrições no uso da terra, bem como a relação entre o PIB do Agronegócio e o PIB da Agropecuária e, ainda, a redução do PIB total do estado.

Pelo fato de o PIB do agronegócio englobar o PIB da agropecuária e das outras atividades vinculadas à agropecuária, a relação da terceira coluna na tabela 4 mostra o quanto o PIB total do estado é afetado quando há uma variação no PIB da agropecuária. Para o estado do Amapá, por exemplo, o qual apresenta uma relação de 2,53, uma redução de $\mathrm{R} \$ 10,00$ no PIB da agropecuária reflete em uma queda de $\mathrm{R} \$$ 25,30 no PIB total da economia. Assim, a redução no PIB total é dada pela multiplicação das colunas dois e três da tabela 4 . O resultado aparece na última coluna da tabela 4. 
Tabela 4. Redução do PIB da Agropecuária, relação dos PIBs do Agronegócio e da Agropecuária e Redução do PIB Total da Economia nos estados selecionados.

\begin{tabular}{lccc}
\hline Estado & $\begin{array}{c}\text { Redução do PIB } \\
\text { da Agropecuária } \\
\text { (em reais) }\end{array}$ & $\begin{array}{c}\text { Relação PIB do } \\
\text { Agronegócio / } \\
\text { PIB da Agropecuária* }\end{array}$ & $\begin{array}{c}\text { Redução do } \\
\text { PIB Total do estado } \\
\text { (em reais) }\end{array}$ \\
\hline Amapá & 83.818 .740 & 2,53 & 212.061 .412 \\
Maranhão & 847.889 .800 & 2,16 & 1.831 .441 .968 \\
Pará & 997.930 .000 & 2,34 & 2.335 .156 .200 \\
Rondônia & 332.242 .100 & 2,27 & 754.189 .567 \\
Roraima & 78.219 .740 & 2,64 & 206.500 .114 \\
\hline
\end{tabular}

Fonte: Dados da pesquisa.

Nota: * Os valores foram extraídos de Guilhoto (2004), que calculou para os estados brasileiros o PIB dos segmentos do Agronegócio para 1999. Supõe-se que as relações existentes em 1999 sejam válidas para 1995.

A maior redução do PIB total ocorreria no estado do Pará (com perda de R\$ 2.335.156.200,00), seguido por Maranhão (queda de R\$1.831.441.968,00), Rondônia (-R\$754.189.567,00), Amapá (- R\$212.061.412,00) e Roraima (- R \$ 206.500.114,00).

A partir dos novos valores do PIB total e per capita (já descontadas as reduções devido à adequação em respeito à legislação ambiental) e, utilizando a expressão 7, é calculado o índice de renda que, combinado com os índices de longevidade e educação, forma o IDH-M para cada estado selecionado. Na tabela 5, aparecem os índices de renda sem e com a restrição do uso do fator terra, os índices de educação e longevidade e o IDH-M sem e com a restrição do fator terra.

Como se pode observar na tabela 5, as reduções no fator terra para esses estados gerariam quedas distintas nos índices de renda.

Tabela 5. Componentes do IDH-M e seu valor para os estados selecionados.

\begin{tabular}{lccccccc}
\hline & \multicolumn{2}{c}{ Índice renda } & & & \multicolumn{2}{c}{ IDH-M } \\
\cline { 2 - 3 } Estado & $\begin{array}{c}\text { Sem restrição } \\
\text { do uso da } \\
\text { terra }\end{array}$ & $\begin{array}{c}\text { Com } \\
\text { restrição do } \\
\text { uso da terra }\end{array}$ & $\begin{array}{c}\text { Índice } \\
\text { Educação }\end{array}$ & $\begin{array}{c}\text { Índice } \\
\text { Longevidade }\end{array}$ & $\begin{array}{c}\text { Sem restrição } \\
\text { do uso da } \\
\text { terra }\end{array}$ & $\begin{array}{c}\text { Com } \\
\text { restrição do } \\
\text { uso da terra }\end{array}$ \\
\hline Amapá & 0,804 & 0,758 & 0,812 & 0,687 & 0,768 & 0,752 \\
Maranhão & 0,576 & 0,492 & 0,646 & 0,578 & 0,600 & 0,572 \\
Pará & 0,715 & 0,660 & 0,757 & 0,678 & 0,717 & 0,698 \\
Rondônia & 0,714 & 0,641 & 0,772 & 0,659 & 0,715 & 0,691 \\
Roraima & 0,679 & 0,580 & 0,802 & 0,656 & 0,712 & 0,679 \\
\hline
\end{tabular}

Fonte: Resultados da pesquisa.

Os estados que tiveram a maior redução do índice de renda foram Maranhão (de 0,576 para 0,492 ) e Roraima (de 0,679 para 0,580 ) - ambos com queda de $14,58 \%$ -, seguidos de Rondônia (de 0,714 para 0,641, redução de 10,22\%), Pará (de 0,715 para 0,660, queda de 7,69\%) e Amapá (de 0,804 para 0,758, baixa de 5,72\%). 
Pelo fato de o IDH-M ser composto de três indicadores e, supondo que os índices de longevidade e de educação não se alteram, as reduções do IDH-M foram, relativamente, inferiores às quedas do índice de renda.

O estado do Amapá, o qual detinha IDH-M de 0,768 sem a restrição do uso da terra, passaria a ter, com o atendimento à legislação, IDH-M de 0,752, o que representa uma redução de $2,08 \%$. Para o estado do Pará, a baixa seria de $2,65 \%$, com o IDH-M passando de 0,717 para 0,698. No estado de Rondônia, o IDH-M cairia de 0,715 para 0,691, correspondendo a uma queda de 3,36\%. A segunda maior redução, de 4,63\%, ocorreria em Roraima, com o IDH-M caindo de 0,712 para 0,679 . E o estado do Maranhão, o qual apresentou a maior queda percentual no índice de renda, também teria a maior redução do IDH-M, cujo índice passaria de 0,600 para 0,572 (queda de 4,67\%). Vale ressaltar que, dentre os estados analisados, o Maranhão é o que apresenta o menor índice de renda, de IDH-M e também, como já visto, o que mais perderia em termos de qualidade de vida, quando restrições ao uso da terra fossem adotadas.

É importante destacar que tais cálculos consideraram as seguintes hipóteses:

1. que as reduções nos usos dos fatores capital e trabalho seriam proporcionais às reduções no uso do fator terra na agropecuária. No entanto, isso pode não ser necessário se, juntamente de restrições ao uso do fator terra, forem adotadas tecnologias poupadoras desse fator, o que implica tecnologias com maior produtividade dos fatores trabalho e capital.

2. apesar das reduções do nível de renda, os índices de longevidade e de saúde permanecem idênticos.

\section{Conclusões}

Com os procedimentos metodológicos e os dados adotados neste trabalho, é possível concluir que o fator terra não é estatisticamente significativo para determinar a renda da produção agropecuária na Amazônia como um todo e em quatro de seus estados. Mas o fator terra é estatisticamente significativo na determinação da renda na agropecuária dos estados do Amapá, Maranhão e Pará. No entanto, capital e trabalho também exercem influências fortes na determinação da renda da agropecuária nesses três estados.

Tal constatação sustenta proposituras de que não haveria a necessidade de incorporar continuamente novas áreas à agropecuária via novos desmatamentos, bastando otimizar o uso das áreas já desmatadas por meio da adoção de técnicas que aumentem a produtividade do capital e trabalho por hectare de terra.

Nesse aspecto, os resultados aqui obtidos ajudam a sustentar algumas proposições de melhor aproveitamento da terra já desmatada e incorporada à produção, a exemplo de Rebello e Homma (2005); e a proposta de Sachs, o qual considera a possibilidade de conversão dos pastos naturais em áreas de aproveitamento agropecuário, em que a "fronteira agrícola poderia avançar, 
mantendo integralmente as florestas intactas" (SACHS, 2004, p. 129). Assim, haveria uma queda no ritmo do desmatamento, e mais áreas permaneceriam em suas situações naturais. No entanto, isso significa um número constante de agentes produtores, constituindo uma barreira à entrada de novos agentes no mercado. Como se sabe, a estrutura da produção agropecuária no Brasil é bastante heterogênea, e esse cenário se reproduz na Amazônia, tanto nas áreas de produção quanto na utilização de capital e trabalho. Essa heterogeneidade se traduz em unidades com maior eficiência na utilização dos fatores de produção, principalmente na produtividade da terra. Assim, deve haver estímulos para que as unidades agropecuárias intensifiquem a produtividade da terra.

Ocorreram reduções expressivas da renda quando se estabelecem restrições ao uso da terra visando atender às exigências legais. No entanto, essas quedas foram menos sensíveis no IDH-M devido ao fato de se supor que os índices de longevidade e educação fiquem constantes; embora seja pertinente estabelecer a ressalva de que tais reduções no IDH-M expressam uma degradação significativa da condição de vida da população local. Como as quedas da renda e do bem-estar não serão distribuídas homogeneamente no espaço físico e há a necessidade de compensar os agentes (agricultores, pecuaristas e trabalhadores rurais, por exemplo) que se virem restringidos no uso da terra, é possível pensar em:

1. uma política de compensação monetária por parte do estado aos produtores rurais, por meio de programas assistencialistas (como a doação de renda mensal em um programa tipo bolsa família e que poderia ser chamado de bolsa floresta ${ }^{9}$ );

2. redefinição dos instrumentos de política agrícola (caso do crédito rural, preços mínimos e de pesquisa agrícola), para serem orientados na região amazônica para a produção florestal sustentável. Esta última permitiria a renda da agropecuária ser, parcialmente ou totalmente, mantida pela exploração da floresta e não pela conversão da floresta em agricultura e pecuária.

Os cálculos e resultados apresentados neste trabalho referem-se ao ano de 1995 e foram realizados antes da divulgação oficial do Censo Agropecuário de 2006. No entanto, não há dados de IDH-M para esse último ano, o que não nos permite, ainda, atualizar o trabalho para considerar o ano de 2006 e comparar os novos resultados com os obtidos para 1995. No entanto, futuros estudos poderão realizar essa comparação quando houver a disponibilidade do IDH-M para 2006.

Também como sugestões para futuras pesquisas têm-se (à medida que novos dados e procedimentos estatísticos surgirem) a de relaxar algumas hipóteses que tiveram de ser adotadas para realizar o presente trabalho, tais como a suposição de que a reserva legal corresponda a $80 \%$ da área total dos estabelecimentos agropecuários (considerando que há áreas dentro da Amazônia em que esse limite é de $20 \%$ ou de $35 \%$ ), bem como a de avaliar os efeitos que reduções na renda trazem sobre o nível de educação e de saúde.

${ }^{9}$ Esta proposta já é implementada pelo Governo do Amazonas, mas em pequena escala. 


\section{Referências Bibliográficas}

ACKERMAN, F. Applied welfare economics: externalities, valuation and cost-benefit analysis. In: ACKERMAN, F.; KIRON, N.R.; GOODWIN, J.M.; HARRIS e GALLAGHER, K. Human Well-Being and Economic Goals, Washington: Island Press, 1997. 474 p.

ANDZIO-BIKA, H.L.; WEI, L. Agricultural productivity growth and technology progress in developing country agriculture: case study in China. Journal of Zhejiang University Science, v. 6, Suplemento I, Hangzhou, 2005.

AZEVEDO, A.A; PASQUIS, R. Da abundância do agronegócio à Caixa de Pandora ambiental: a retórica do desenvolvimento (in) sustentável do Mato Grosso. In: CONGRESSO DA SOCIEDADE BRASILEIRA DE ECONOMIA E SOCIOLOGIA RURAL, 44., 2006, Fortaleza, Anais ... Fortaleza: SOBER, 23 a 27 jul. 2006.

BARRETO, P.; SOUZA JÚNIOR, C.; NOGUERÓN, R.; ANDERSON, A.; SALOMÃO, R. Pressão humana da floresta Amazônica brasileira. Belém: WRI/Imazon, 2005. 84 p.

BARROS, R. P.; MENDONÇA, R.S.P.; DUARTE, R.P.N. Bem-estar, pobreza e desigualdade de renda: uma avaliação da evolução histórica e das disparidades regionais. Brasília: IPEA. 1997. (Texto para Discussão, 454).

BARROS, E. S., COSTA, E. F. \& SAMPAIO, Y. Análise da eficiência utilizando fronteiras paramétricas Cobb-Douglas e Translog: o caso das empresas agrícolas do pólo Petrolina-Juazeiro. Revista Econômica do Nordeste, Fortaleza, v. 35, n. 1. p. 7-19, 2004.

BINICI, T.; DEMIRCAN, V.; ZALAUF, C.R. Assessing production efficiency of dairy farms in Burdur Province, Turkey. Jornal of Agriculture and Rural Development in the Tropics and the Subtropics. v. 107, n. 1, 2006.

BOADWAY, R.; BRUCE, N. Welfare Economic. New York: Basil Blackwell Inc., 1984.

BONELLI, R. Impactos econômicos e sociais de longo prazo da expansão agropecuária no Brasil: revolução invisível e inclusão social.: Brasília: IPEA, 2001. (Texto para discussão, 838).

BRANDÃO, A. S. P., REZENDE, G. C. \& MARQUES, R. W.C. Agricultural growth in Brazil in the period 1999-2004: outburst in soybeans livestock and its impact on environment. Texto para Discussão n. 1103. Rio de Janeiro: IPEA, 2005.

BRAVO-ORTEGA, C.; LEDERMAN, D. Agriculture and national welfare around the world: causality and international heterogeneity since 1960. Policy Research working paper series ; no. WPS 3499. Disponível em: < http://www-wds.worldbank.org/external/ default/WDSContentServer/IW3P/IB/2005/02/25/000090341_20050225104637/Rendere d/PDF/wps3499.pdf> Acesso em: 13 fev. 2008. 
CALENTANO, D.; VERÍSSIMO. A. A Amazônia e os objetivos do milênio. Belém: Imazon. 2007a.

CALENTANO, D.; VERÍSSIMO, A. O avanço da fronteira Amazônica: do boom ao colapso. Belém: Imazon, 2007b. Disponível em: < http://www.museu-goeldi.br/sobre/ NOTICIAS/pdf_apresentacoes_simposio/BetoVerissimo.pdf $>$. Acesso em: 13 jan. 2008.

CHOWDHURY, S.R.; NAGADEVARA, V.; HEADY, E.O. A Bayesian Application on Cobb-Douglas Production Function. American Journal of Agricultural Economics, Menasha, v. 57, n. 2, p. 361-363, 1975.

COOTER, R.; RAPPOPORT, P. Were the ordinalists wrong about welfare economics. Journal of Economic Literature, Pittsburgh, v. 22, n. 2, p. 507-530, 1984.

DEATON, A.; MUELBAUER, J. Economics and consumer behavior. Cambridge: Cambridge University Press, 1980.

DIENER, E. A value based index for measuring national quality of life. Social Indicators Research. v. 36, Dordrecht, Oct. 1995.

DINIZ, M.B.; NASCIMENTO, R.B.S.; DINIZ, M.J.T..; PUTY, C.C.B.; RIVERO, S.L.M. A Amazônia (Legal) brasileira: evidências de uma condição de armadilha da pobreza? In: Anais do Encontro Nacional de Pós Graduação em Economia, Belo Horizonte, 2007.

ECHEVARRIA, C. A three-factor agricultural production function: the case of Canadá. In: International Economic Journal, v. 12, n. 3, 1998.

FEARNSIDE, P.M.; GRAÇA, P.M.L.A. BR-319: Brazil's Manaus-Porto Velho highway and the potential impact of linking the arc of deforestation to central Amazonia. Environmental Management, New York, v. 38, n. 2, p. 705-716, 2006.

FÜSSEL, H.M. Methodological and empirical flaws in the design and application of simple climate-economy models. In: Climatic Change. v. 31. Dordrecht, Mar. 2007.

GALOR, O.; MOAV, O; VOLLRATH, D. Land inequality and the emergence of human capital promoting institutions. CEPR Discussion Paper, 3817. 2005. Acessível em: <http://www.brown.edu/Departments/Economics/Papers/2005/2005-03_paper.pdf> . Acesso em: 15 jan. 2008.

GERLAGH, R.; KEYZER, M.A. Efficiency of conservationist measures: An optimist viewpoint. In: Journal of Environmental Economics and Management. New York, v. 46, n. 2, p. 310-333, Sep. 2003.

GOMES, G.M.; VERGOLINO, J.R. Trinta e cinco anos de crescimento econômico na Amazônia (1960/1995). Brasília: IPEA, 1997. (Texto para discussão, 533). 
GUILHOTO, J. J. M. The Regional (State Level) Importance of the Agribusiness GDP in the Brazilian Economy. In: XXXII Encontro Nacional de Economia, 2004, João Pessoa-PB. Anais do XXXII Encontro Nacional de Economia, 2004.

HADDAD, P.R.; BONELLI, R. Desenvolvimento humano e condições de vida: indicadores brasileiros. Brasília: PNUD, IPEA, FJP, IBGE, 1988.

HARDIE, I.W.; PARKS, P.J.; VAN G. KOOTEN, G.C. The economics of land use at the intensive and extensive margins. In: TIETENBERG; H. FOLMER (Eds.). The International Yearbook of Environmental E Resource Economics 2004/2005. A Survey of Current Issues. Cheltenham: Edward Elgar, 2004.

HASSELMANN, K. Intertemporal Accounting of Climate Change - Harmonizing Economic Efficiency and Climate Stewardship. In: Climatic Change. v. 41, Dordrecht: Mar 1999.

HAYAMI, Y. On the use of the Cobb-Douglas production function on the cross-country analysis of agricultural production. American Journal of Agricultural Economics, Menasha, v. 52, n. 2, p. 327-329, 1970.

HOMMA, A.K.O. Produção rural: empresarial e familiar. Plano de Desenvolvimento sustentável da Amazônia Legal: Estudos diagnósticos setoriais - PDSA 2005-2008. Agência de Desenvolvimento da Amazônia, Universidade Federal do Pará, Organização dos Estados Americanos. - Belém: ADA, 2006.

IVANOVA, I.; ARCELUS, F.J.; SRINIVASAN, G. An assessment of the measurement properties of the human development index. In: Social Indicators Research, n. 46, 1999.

ISLAM, S.; CLARKE, M. Measuring the quality of life: a new approach empirically applied to Thailand, paper presented at INDEX2001 Quality of Life Indicators Conference,Rome 2-5 Oct., 2001.

JUDGE, G.G.; HILL, R.C.; GRIFFITHS, W.E.; LÜTKEPOHL, H.; LEE, T.C. Introduction to the theory and practice of econometrics. New York: John Wiley \& Sons, 1982. $1024 \mathrm{p}$.

KAMAT, M.S.; TUPE, S.N.; KAMAT, M.M. Indian agriculture in the new economic regime, 1971-2003: Empirics based on the Cobb Douglas Production Function. Disponível em: <http://mpra.ub.uni-muenchen.de/6150> . Acesso em: 10 jan. 2008.

LAURANCE, W.F.; ALBERNAZ, A.K.M.; FERARNSIDE, P.M.; VASCONCELOS, H.L.; FERREIRA, L.V. Deforestation in Amazonia. Science, Washington, n. 304, p. 1109-1111, 2004.

MARGULIS, S. Causas do desmatamento da Amazônia brasileira. Brasília: Banco Mundial, 2003. 100 p. 
MARINHO, E.L.L.; SOARES, F.A.; BENEGAS, M. Desigualdade de renda e eficiência na geração de bem-gestar. Revista Brasileira de Economia, Rio de Janeiro, v. 58, n. 4 , p. 583-608, 2003.

MILL, J.S. Princípios de economia política. São Paulo: Editora Abril, 1983, 360 p.

MUKHOPADHAYA, P. Efficiency criteria and the sen-type social welfare function. National University of Singapore. Departament of Economics, 2001. (Working Paper, 0114).

MURATA, M.H.; LOPES, L.R. Elasticidade de substituição entre os fatores de produção capital e trabalho da economia brasileira: uma análise de dados em painel para o período 1990 a 2003. In: ENCONTRO NACIONAL DA ABER, 4., 2006, Foz do Iguaçu, 2006. Disponível em: <http://www.pce.uem.br/artigos/12.pdf> Acesso em: 12 jan. 2008.

OLSON, L.J. Dynamic efficiency of conservation of renewable resources under uncertainty. Journal of Economic Theory. New York, v. 95, n.2, p. 186-214, 2000.

PEARCE, D.; NASH,C., The social appraisal of projects, London: Macmillan, 1981,152 p.

QIZILBASH, M. On the measurement of human development. Lecture prepared for de UNDP training course, School of economic and social studies, Norwich, 2002.

RAMOS, L.; ÁVILA, M. Nível de bem-estar social no Brasil metropolitano: uma comparação inter-regional. Brasília: IPEA. 2000. (Texto para Discussão, 730).

REBELLO, F.K.; HOMMA, A.K.O. Uso da terra na Amazônia: uma proposta para reduzir desmatamentos e queimadas. Ciência \& Desenvolvimento, Belém, v.1, n.1, p. 199-236, jul./dez. 2005.

RUIJS, A. Welfare and distribution effects of water pricing policies. 2007. Disponível em: < http://ssrn.com/abstract=1017476>. Acesso em: 15 jan. 2008.

SACHS, I. Desenvolvimento includente, sustentável e sustentado. Rio de Janeiro: Garamond, 2004. 152 p.

SANTOS, B.S. Ética e "felicidade" em Platão e Aristóteles: semelhanças, tensões e convergências In: Caderno de Atas da Anpof, 2001.

SARRIS, A.H. O papel da agricultura no desenvolvimento econômico e na diminuição da pobreza: uma base empírica e conceitual. 2001. Disponível em: $<$ http://www.nead.org.br/download.php?form $=$ pdf\&id=46>. Acesso em: 12 jan. 2008.

SEN, A. Social choice theory: a re-examination. Econometrica, v. 45, n. 1. p. 43-48, Jan. 1977. 
SEN, A. Sobre ética e economia. São Paulo: Cia das Letras, 1999. 144 p.

SEN, A. Desenvolvimento como liberdade. São Paulo: Cia das Letras, 2000. 409 p.

SILBERBERG, E.; SUEN. The structure of economics, 3. Ed. Boston, Mass.: McGraw-Hill, 2001. 688 p.

SOUZA, I.F. Desenvolvimento do norte de Mato Grosso e suas implicações econômicas, ambientais e sociais. In: $5^{\mathbf{a}}$ Mostra de Iniciação Científica do Sul de Mato Grosso. Rondonópolis, 2007. Disponível em: < http://www.unir-roo.br/mostra/arquivos/ 2007/1192533759.pdf>. Acesso em: 13 jan. 2008.

VOLPI, G. Climate mitigation, deforestation and human development in Brazil. Human Development Report 2007/2008, disponível em < http:/hdr.undp.org/en/reports/ global/hdr2007-2008/papers/volpi_giulio.pdf > . Acesso em 21 de outubro de 2009.

WALKER, R.T.; HOMMA, A.K.O.; CONTO, A.J.; CARVALHO, R.A.; FERREIRA, C.A.P.; SANTOS, A.IM.; ROCHA, A.C.P.N.; OLIVEIRA, P.M.; RODRIGUES-PEDRAZZA, C.D. As contradições do processo de desenvolvimento agrícola na Transamazônica. Belém: Embrapa Amazônia Oriental, 117 p. 1997. (Embrapa Amazônia Oriental, Documentos, 93).

WELZEL, C.; INGLEHART, R; KLINGEMANN, H.D. The theory of human development: A cross-cultural analysis. European Journal of Political Research, v. 42, n. 3, p. 341-379, 2003.

WEINHOLD, D.; REIS E.J. Model evaluation and causality testing in short panels: the case of infrastructure provision and population growth in the Brazilian Amazon. Journal of Regional Science, London, v. 41, n. 4, p. 639-658, 1999.

ZAGONARI, F. International pollution problems: Unilateral initiatives by environmental groups in one country. Journal of Environmental Economics and Management. New York, v. 36, n. 1, p. 36-49, Jul. 1998. 